\title{
Energy Valorization of Food Waste: Rapid Conversion of Typical Polysaccharide Components to Formate
}

\author{
Guodong Yao ${ }^{\mathrm{a}}$, Yalin Guo ${ }^{\mathrm{b}}$, Yi Le ${ }^{\mathrm{b}}$, Binbin Jin ${ }^{\mathrm{b}}$, Runtian $\mathrm{He}^{\mathrm{b}}$, Heng Zhong ${ }^{\mathrm{b}, *}$, Fangming Jin ${ }^{\mathrm{b}, \mathrm{c} *}$ \\ ${ }^{a}$ State Key Laboratory of Pollution Control and Resources Reuse, College of Environmental Science \\ and Engineering, Tongji University, 1239 Siping Road, Shanghai 200092, China \\ b School of Environmental Science and Engineering, State key lab of metal matrix composites, \\ Shanghai Jiao Tong University, 800 Dongchuan Road, Shanghai 200240, China \\ c Shanghai Institute of Pollution Control and Ecological Security, Shanghai 200092, China
}

\section{SUPPORTING INFORMATION}

This supporting information includes 1 table and 4 figures. There are in total 4 pages. 
Table S1 Carbon and water contents of the feedstocks.

\begin{tabular}{cc}
\hline Material & Carbon content ${ }^{\mathrm{a}}(\mathrm{wt} \%)$ \\
\hline Starch & $44.4^{\mathrm{b}}$ \\
Cellulose & $44.4^{\mathrm{b}}$ \\
Rice & 40.6 \\
Wheat & 41.4 \\
Potato & 40.7 \\
Carrot & 37.6 \\
Pork & 66.7 \\
Tissue & 40.9 \\
\hline
\end{tabular}

${ }^{a}$ dry material. ${ }^{b}$ calculated value.

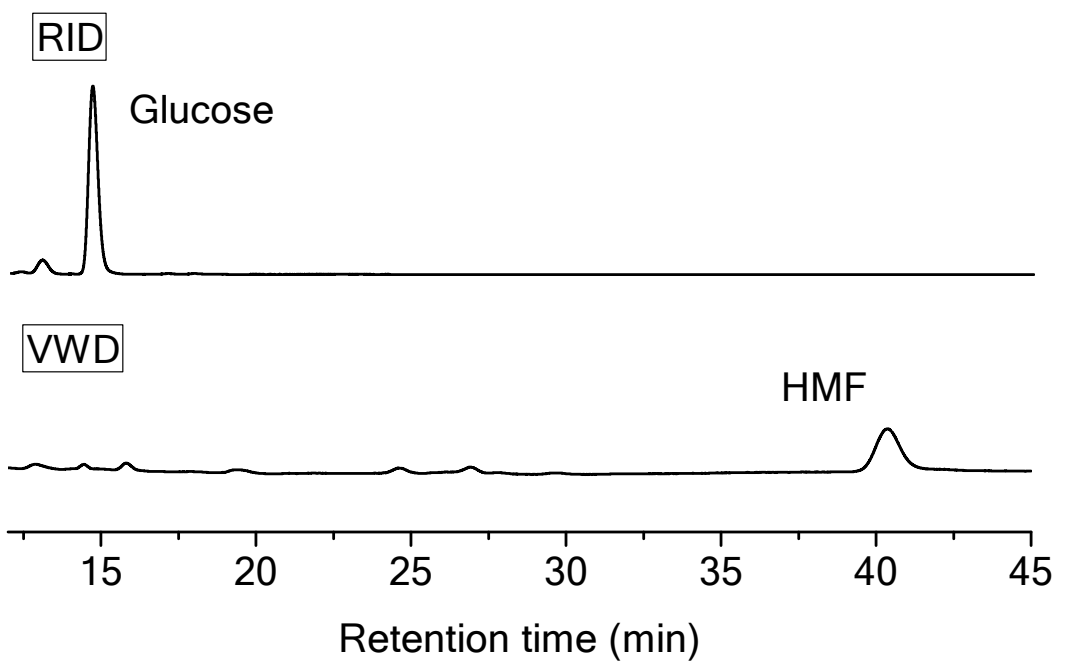

Figure S1. HPLC chromatograms of products from starch after acid pretreatment (160 ${ }^{\circ} \mathrm{C}, 30 \mathrm{~min}, 1.2 \mathrm{~mol} / \mathrm{L} \mathrm{HCl}, 0.2 \mathrm{~g}$ starch, $4 \mathrm{~mL} \mathrm{HCl}$ ). 


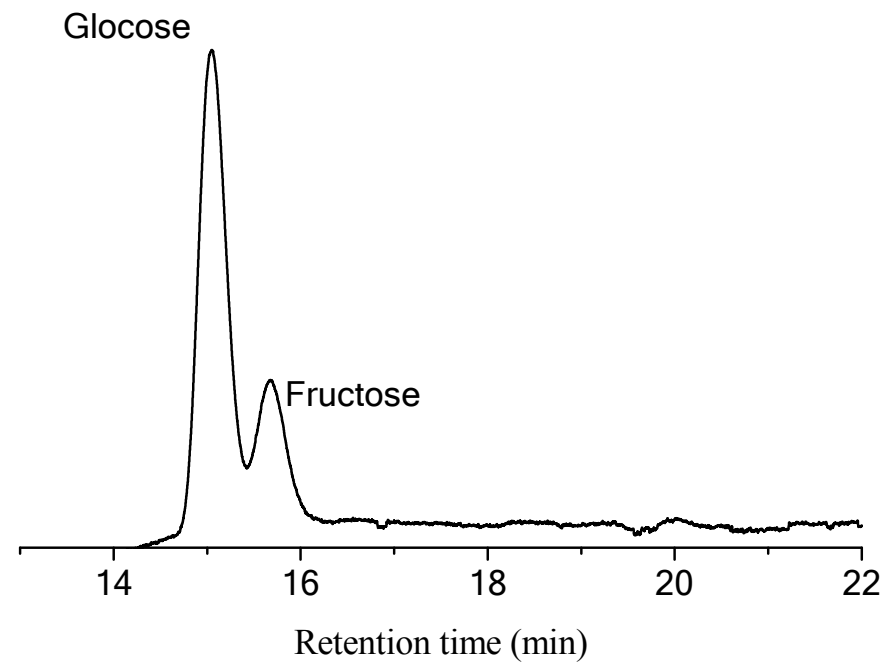

Figure S2. HPLC chromatograms of the products from cellulose after acid pretreatment $\left(160{ }^{\circ} \mathrm{C}, 60 \mathrm{~min}, 1.2 \mathrm{~mol} / \mathrm{L} \mathrm{HCl}, 0.05 \mathrm{~g}\right.$ cellulose, $4 \mathrm{~mL} \mathrm{HCl}$, RI detection).

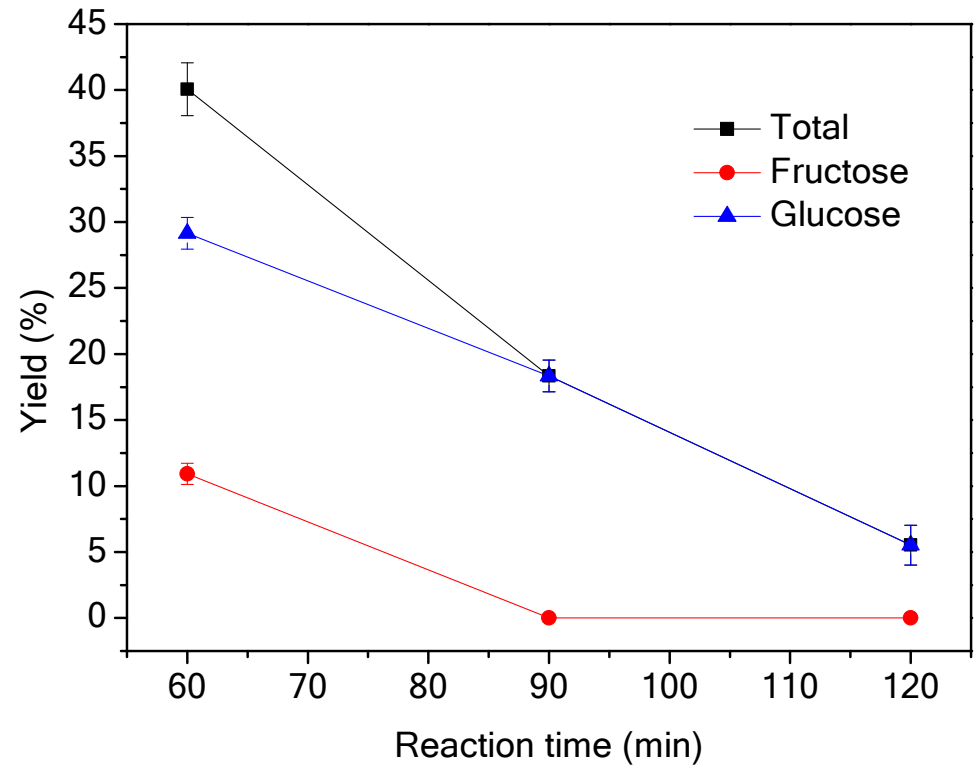

Figure S3. Effect of reaction time of acid pretreatment on the yield of fructose and glucose from cellulose $\left(160^{\circ} \mathrm{C}, 3.1 \mathrm{~g} / \mathrm{L}\right.$ cellulose, $\left.1.2 \mathrm{~mol} / \mathrm{L} \mathrm{HCl}\right)$. 


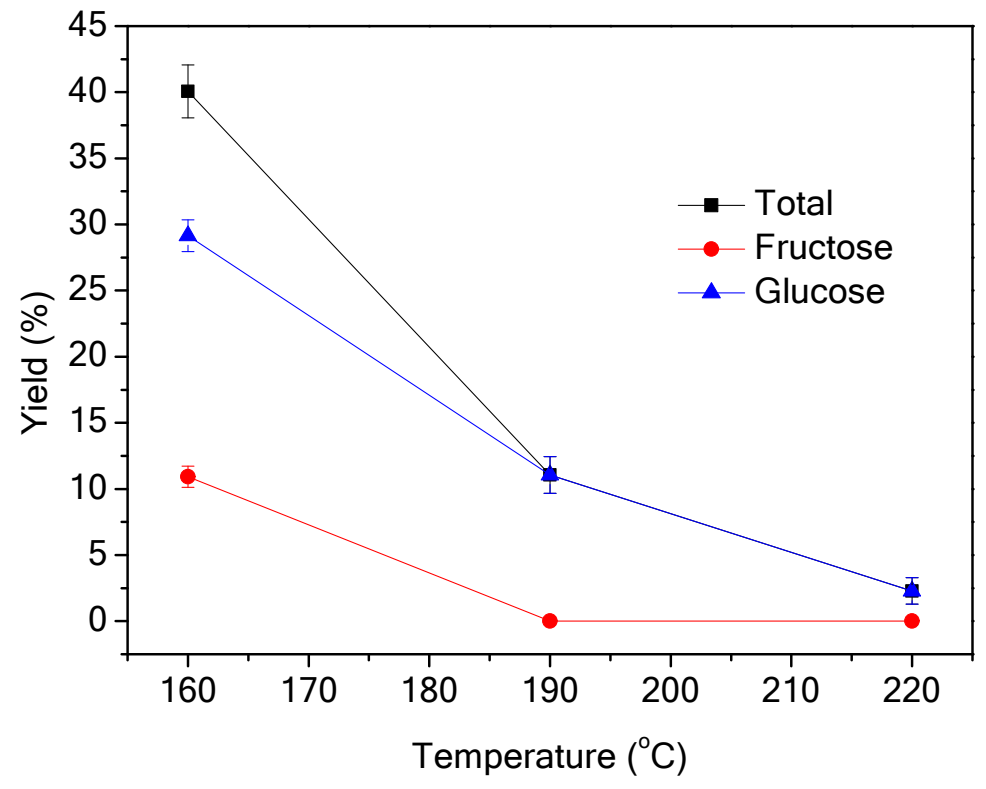

Figure S4. Effect of temperature of acid pretreatment on the yield of fructose and glucose from cellulose (60 min, $3.1 \mathrm{~g} / \mathrm{L}$ cellulose, $1.2 \mathrm{~mol} / \mathrm{L} \mathrm{HCl}$ ). 